\title{
Potential of Polyherbal Formulation in Burn Wound Model
}

Swati Mishra ${ }^{1 *}$, R. K. Mishra ${ }^{1}$, Sruti Ranjan Mishra ${ }^{1}$, Himesh Soni ${ }^{2}$

${ }^{1}$ Danteswari College of Pharmacy, Borpadar, Jagdalpur, Chhattisgarh, India

${ }^{2}$ D. H. S. Bhopal, Madhya Pradesh, India

DOI: $10.36348 /$ sijtcm.2022.v05i01.003 | Received: 08.12.2021 | Accepted: 25.01.2022 | Published: 29.01.2022

*Corresponding author: Swati Mishra

Danteswari College of Pharmacy, Borpadar, Jagdalpur, Chhattisgarh, India

\section{Abstract}

Polyherbal formula has been used everywhere in the global because of its medicinal and healing application. It has additionally referred to as polyherbal therapy or herb-herb combination. In an age of integrated healthcare where Ayush therapies are being accepted along side the fashionable medicine, we see that these are separate compartments in theory and practice. Wound healing begins at the time of injury and can last for a variety of times depending on the severity of the wound. The wound healing process can be divided into three stages: the inflammatory phase, the proliferative phase, and finally the remodelling phase, which determines the strength and appearance of the healed tissues. In the present work an attempt had been made to evaluate wound healing potential of Polyherbal formulation contains Punica granatum and Coleus aromaticus extract in burn wound model.

Keywords: Wound healing, Polyherbal formulation, P.granatum \& C.aromaticus.

Copyright $\odot 2022$ The Author(s): This is an open-access article distributed under the terms of the Creative Commons Attribution 4.0 International License (CC BY-NC 4.0) which permits unrestricted use, distribution, and reproduction in any medium for non-commercial use provided the original author and source are credited.

\section{INTRODUCTION}

Herbal medicines are extremely important in health-care systems, particularly in developing nations. In ancient Indian literature, medicinal plants are defined as possible sources of therapeutic ingredients in a very broad logic [1]. The number of patients seeking alternative and herbal treatments is rapidly increasing. For hundreds of years, herbal medicines have been the synthesis of therapeutic experiences of generations of practising physicians of indigenous systems of medicine. Herbal medications are in high demand for basic health care in the poor countries, not only because they are less expensive, but also because they are more culturally acceptable, have greater compatibility with the human body, and have less adverse effects [2]. Wound healing begins at the time of injury and can last for a variety of times depending on the severity of the wound. The wound healing process can be divided into three stages: the inflammatory phase, the proliferative phase, and finally the remodeling phase, which determines the strength and appearance of the healed tissues [3].

\section{Phase of wound healing [4]}

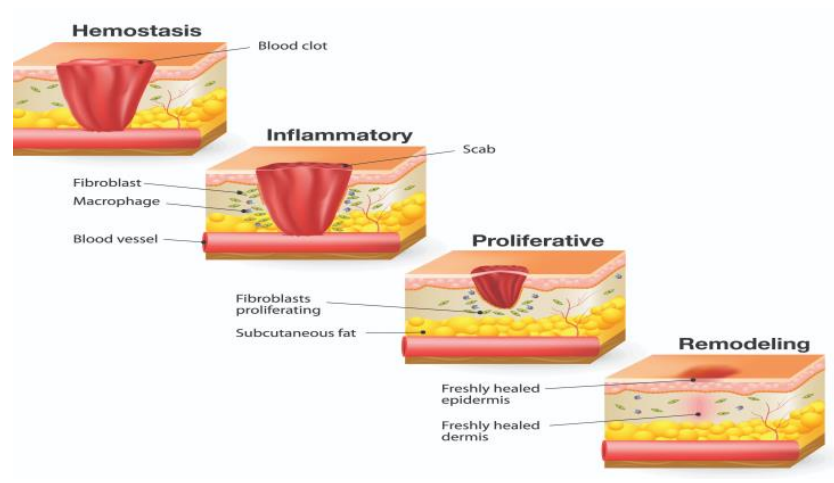


Alternative reasserts of drug treatments like natural drug treatments may also quickly come to be key additives within side the healthcare provision enterprise for each people and animals mainly in growing countries. These natural drug treatments will fill an opening resulting from a lower with inside the quantity of latest cutting-edge drug treatments being evolved within side the previous few decades (mainly with the case with anti-infective), growing costs, drug resistance, and aspect outcomes of cutting-edge pharmaceuticals [5]. Most herbs or components thereof incorporate Phytoconstituent which have huge ranging medicinal value like antimicrobial, anti-inflammatory, antioxidant, antipruritic, hypotensive, proliferative, hypoglycemic, and analgesic which are regularly key role in wound control or healing ${ }^{6}$. In the present work an attempt had been made to evaluate wound healing potential of Polyherbal formulation contains Punica granatum and Coleus aromaticus extract in burn wound model.

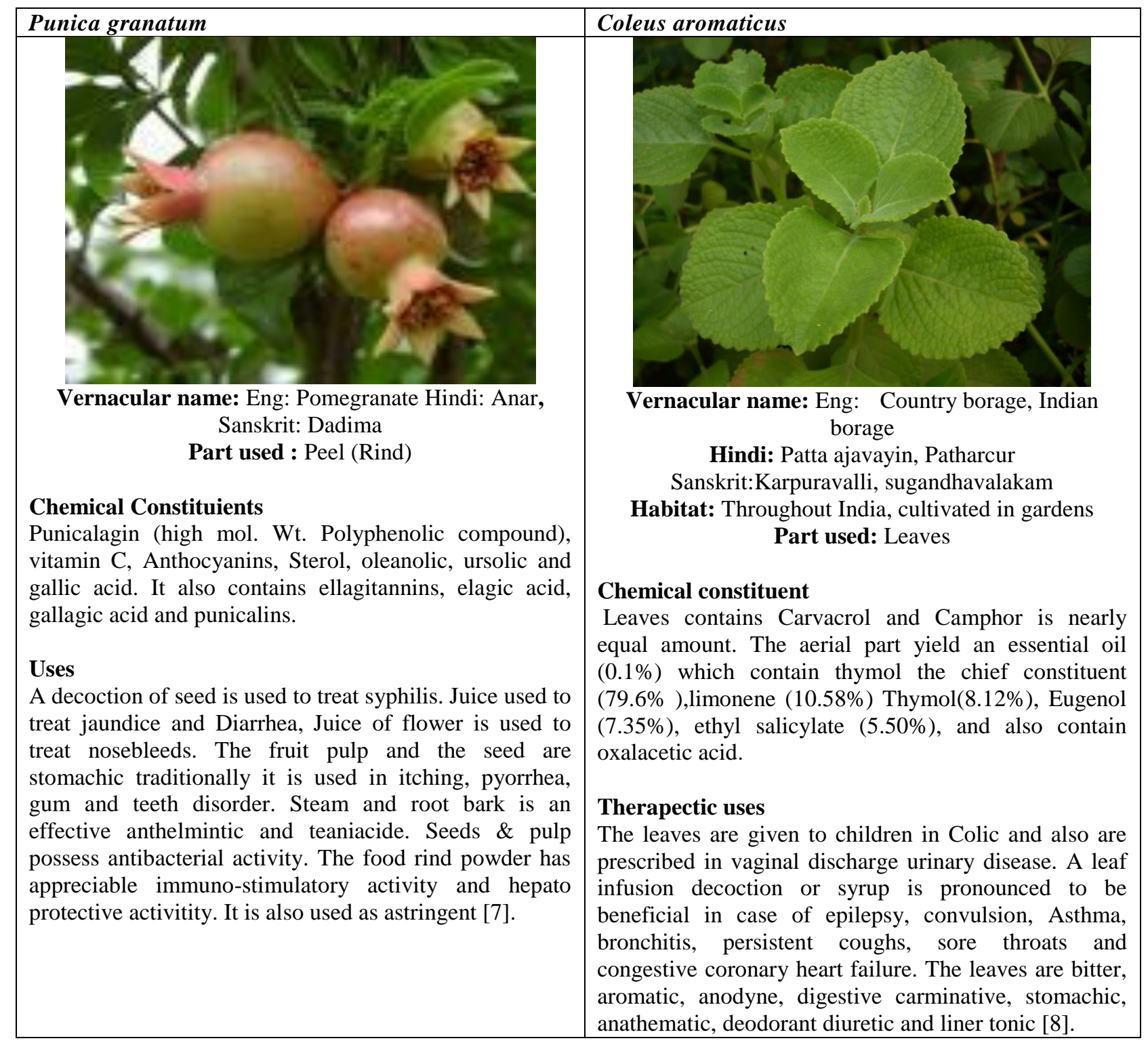

\section{MATERIAL AND METHODS SELECTION OF PLANTS}

The plants were selected on the basis of their anti inflammatory activities, chemical constituent and wide medicinal uses in the traditional literatures. The ease of availability of plant is also taken into consideration during selection.

Rind (Peel) of Punica granatum (Anar)

Leaves of Coleus aromaticus (Patta Ajavayin)

\section{Collection and Authentication}

The plant work collected in the month of September - October 2021 locally from Bhopal (M.P.). and authenticated.

\section{Extraction}

\section{Coleus aromaticus}

Approximately $200 \mathrm{~g}$ of powder crude drug were separately extracted with Hydroalcoholic solvent [Ethanol: water (70:30)] by double maceration and 
Swati Mishra et al., Sch Int J Tradit Complement Med, Jan, 2022; 5(1): 19-23

recovered the solvent by distillation and combined extract of each drug were concentrated under reduced pressure and air dried.

Punica granatum: The powder crude drug were separately extracted with methanol by soxhelation method.

\section{FORMULATION PREPARATION}

After preparation of extract and phytochemical studies, the next step was to formulate a polyherbal preparation. An ointment with water soluble base was of first choice due to their ease of preparation and also eases of cleaning after application [9].

Three formulations were prepared by Fusion Method

1-Punica granatum extract $(10 \% \mathrm{w} / \mathrm{w})$

\section{- TEST I}

2- Coleus aromaticus extract $(10 \% \mathrm{w} / \mathrm{w})$

- TEST II

3- Polyherbal (Punica granatum : Coleus aromaticus $5: 5 \%$ - TEST III

OINTMENT BASE - Hydrophilic ointment USP

Methyl paraben - $0.25 \mathrm{~g}$

Propyl paraben $-0.15 \mathrm{~g}$

Sodum lauryl sulphate - $10 \mathrm{~g}$

Propylene glycol - $120 \mathrm{~g}$

Stearyl alchol - $250 \mathrm{~g}$

White petrolatum - $250 \mathrm{~g}$

Purified water $-370 \mathrm{~g}$ to make about $1000 \mathrm{~g}$.

\section{Procedure}

Melted the stearyl alchol \& white petrolatum on a steam bath $\&$ warmed to abut $75^{0 \mathrm{c}}$. Added the other ingredients with drug extracts, previously dissolved in the water \& warmed to $75^{\circ} \mathrm{C} \&$ stir the mixture until it congeals .

\section{Evaluation of prepared formulation}

Ointment should be stable and uniform so that will make it easy to use under different conditions and will also be stable for a sufficient period of time. Thus, the prepared formulations were subjected to various tests to determine the following parameters.

- Physical appearance

- Stability

- $\mathrm{pH}$

- Irritant effect

\section{Physical appearance:-}

- Hydrophilic USP ointment base - White to cream

- Test-I formulation

- Test-II formulation

- Test-III formulation
- Reddish brown

- Green brown

- Greenish brown

\section{Physical stability}

The prepared formulations were stored at room temperature and at elevated temperatures $40 \pm 2^{\circ} \mathrm{C}$ for 30 days. After two weeks interval, the formulation was tested for its physical characteristics like color and odor.

pH

The $\mathrm{pH}$ of the formulation was determined using $\mathrm{pH}$-meter. The $\mathrm{pH}$ of the all formulations was found between 6.5 to 7.5 .

\section{Irritant effect}

Healthy albino rats, weighing 150-200gm were selected for the study. Rats were caged individually. 24 hours prior to the test, rats depilated by removing hairs at the dorsal thoracic region. The test sites were cleaned with surgical spirit. Measured quantity of the formulation was applied over the respective test sites. The tested animals were observed for any irritation for $48 \mathrm{hr}$ after application.

\section{Controlled partial skin thickness burn model}

Partial-thickness burn wound ( 2 by $2.5 \mathrm{~cm}$ ) was created on a shaved area of the animals dorsal skin, modifying a method described by Smahel.8 Briefly, the animals were anaesthetized and shaved. A steel plate 2 $\mathrm{mm}$ thick was heated in boiling water for $7 \mathrm{~min}$ and applied firmly to the skin for $12 \mathrm{sec}$. After creating the wound the animals were housed individually and wound contraction was measured on $2^{\text {nd }}, 4^{\text {th }}, 6^{\text {th }}, 8^{\text {th }}$, $10^{\text {th }}, 12^{\text {th }}, 14^{\text {th }}$ days [10].

\section{Wound Contraction}

Studied by tracing the raw wound area on transparent polythene paper on each alternate days. Later the area assessed using graph paper. The wound contraction was measured as the percentage decrease of original wound size $300 \mathrm{~mm}^{2}$ for each animal group.

\section{RESULT AND DISCUSSION}

In this work Polyherbal formulation containing C.aromaticus leave extract and P.granatum rind extract was taken in consideration to evaluate wound healing potential with reference to burn wound model. The hydrophilic ointment USP base was taken as drug delivery system and prepared formulation was evaluated for their stability. The result was tabulated in table.1. . The $\mathrm{pH}$ of the all formulations was found between 6.5 to 7.5. The irritant effect was tested in healthily albino rats and no sign of irritation were found. The $\%$ wound contractions of C.aromaticus, P.granatum and polyherbal were found to be $78.4 \%$, $86 \%$ and $87.4 \%$ respectively at $14^{\text {th }}$ day. Studies proven that selected individual plants contained rich quantity of phenolics and flavonoids and their polyherbal combination. In Burn wound model wound contraction was measured in $2^{\text {nd }}, 4^{\text {th }}, 6^{\text {th }}, 8^{\text {th }}, 10^{\text {th }}, 12^{\text {th }}, 14^{\text {th }}$ days and it may be seen that the fastest healing of wound 
Swati Mishra et al., Sch Int J Tradit Complement Med, Jan, 2022; 5(1): 19-23

took place in case of animals treated with Polyherbal extract than the control.

Table 1: Stability Parameters of Formulation

\begin{tabular}{|l|l|l|l|l|l|}
\hline \multirow{2}{*}{ S. No } & \multirow{2}{*}{ Parameters } & \multicolumn{3}{|l|}{ Temperature } & $\mathbf{A t} \mathbf{4 0}^{\mathbf{0}} \mathbf{C}$ \\
\cline { 3 - 6 } & & & At Room & 15 days & 30 days \\
\cline { 3 - 6 } & & 15 days & 30 days & No Change & No Change \\
\hline 1. & Colour & No Change & No Change & No Change & No Change \\
\hline 2. & Odour & No Change & No Change & No Change \\
\hline
\end{tabular}

Table 2: Mean Percentage closure of Burn wound area by Topical route on following post wounding days

\begin{tabular}{|c|c|c|c|c|}
\hline \multirow{2}{*}{$\begin{array}{l}\text { Post wounding } \\
\text { days }\end{array}$} & \multicolumn{4}{|c|}{ Wounding Area $\left(\mathrm{mm}^{2}\right)$} \\
\hline & Control & Punica granatum & Coleus aromaticus & Polyherbal \\
\hline 0 & $181.40 \pm 2.22$ & $185.67 \pm 0.42$ & $186.50 \pm 0.67$ & $188.50 \pm 0.67$ \\
\hline 2 & $170.91 \pm 1.2(5.78 \%)$ & $\begin{array}{l}174.71 \pm 0.39 \\
(5.9 \%)\end{array}$ & $\begin{array}{l}175.68 \pm 0.63 \\
(5.8 \%)\end{array}$ & $\begin{array}{l}177.15 \pm 0.64 \\
(6 \%)\end{array}$ \\
\hline 4 & $\begin{array}{l}156.00 \pm 0.63 \\
(33.74 \%)\end{array}$ & $\begin{array}{l}158.19 \pm 0.35 \\
(14.8 \%)\end{array}$ & $\begin{array}{l}162.08 \pm 2.79 \\
(14.7 \%)\end{array}$ & $\begin{array}{l}157.95 \pm 0.55 \\
(16.2 \%)\end{array}$ \\
\hline 6 & $\begin{array}{l}139.67 \pm 0.94 \\
(39.16 \%)\end{array}$ & $\begin{array}{l}141.66 \pm 0.32 \\
(23.7 \%)\end{array}$ & $\begin{array}{l}144.72 \pm 0.51 \\
(22.4 \%)\end{array}$ & $\begin{array}{l}144.48 \pm 0.48 \\
(23.5 \%)\end{array}$ \\
\hline 8 & $\begin{array}{l}99.68 \pm 0.93 \\
(45.05 \%)\end{array}$ & $\begin{array}{l}96.54 \pm 0.21 \\
(48 \%)\end{array}$ & $\begin{array}{l}91.38 \pm 0.32 \\
(51 \%)\end{array}$ & $\begin{array}{l}98 \pm 0.34 \\
(48 \%)\end{array}$ \\
\hline 10 & $\begin{array}{l}81.40 \pm 2.22 \\
(55.13 \%)\end{array}$ & $\begin{array}{l}81.69 \pm 0.18 \\
(56 \%)\end{array}$ & $\begin{array}{l}69.38 \pm 0.25 \\
(62.8 \%)\end{array}$ & $\begin{array}{l}81.05 \pm 0.28 \\
(57 \%)\end{array}$ \\
\hline 12 & $\begin{array}{l}39.75 \pm 1.33 \\
(78.09 \%)\end{array}$ & $\begin{array}{l}38.8 \pm 0.88 \\
(79.1 \%)\end{array}$ & $\begin{array}{l}55.76 \pm 0.20 \\
(70.1 \%)\end{array}$ & $\begin{array}{l}37.7 \pm 0.13 \\
(80 \%)\end{array}$ \\
\hline 14 & $\begin{array}{l}25.44 \pm 1.01 \\
(85.98 \%)\end{array}$ & $\begin{array}{l}25.99 \pm 0.059 \\
(86 \%)\end{array}$ & $\begin{array}{l}40.28 \pm 0.14 \\
(78.4 \%)\end{array}$ & $\begin{array}{l}23.75 \pm 0.84 \\
(87.4 \%)\end{array}$ \\
\hline
\end{tabular}

Value are expressed as the Mean \pm SEM, $n=6$ in each group $P<0.001$ significance Vs control

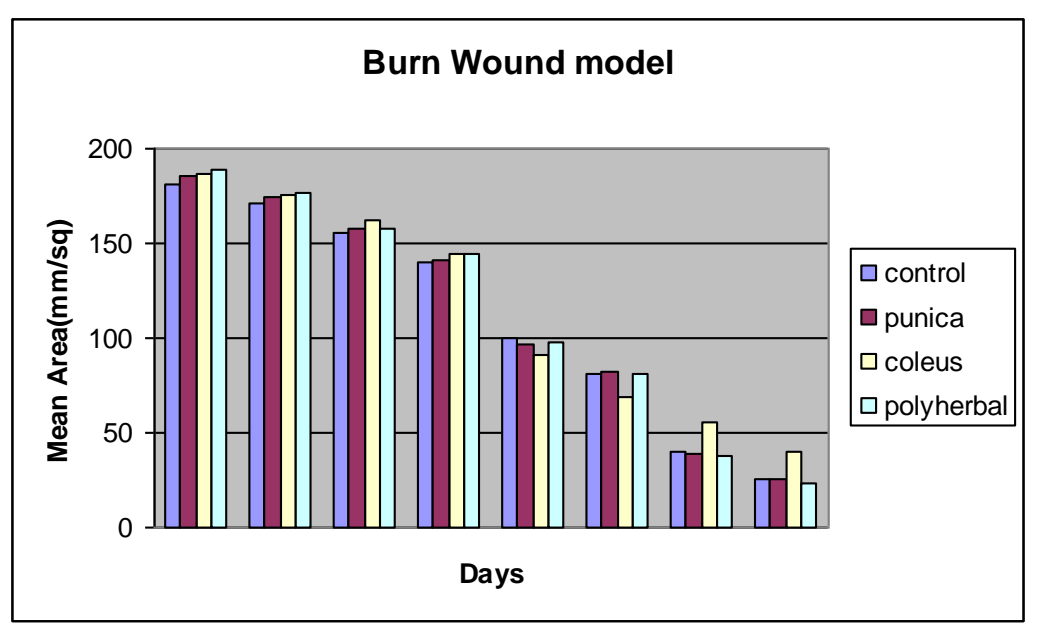

Fig 1: \% wound contraction

\section{CONCLUSION}

On the basis of the results obtained in the present investigation, it is possible to conclude that the ointment of the C.aromaticus, P.granatum and polyherbal extract has significant wound healing potential by synergestic effect of phenolic and flavonoids present in the extract. The above findings justify the wound healing properties of these plants.

\section{REFERENCE}

1. Soni, H., Mishra, K., Sharma, S., \& Singhai, A. K. (2012). Characterization of Azadirachtin from ethanolic extract of leaves of Azadirachta indica. Journal of Pharmacy Research, 5(1), 199201.

2. Sangeeta, S. K. (2020). Herbaceuticals: A Review. International Journal of Pharma O2, 2(1), 80.

3. Soni, H., \& Singhai, A. K. (2012). A recent update of botanicals for wound healing activity. International Research Journal of Pharmacy, 3(7), 1-7.

4. Blee, T. H., Cogbill, T. H., \& Lambert, P. J. (2002). Hemorrhage associated with vitamin C 
deficiency in surgical patients. Surgery, 131(4), 408-412.

5. Himesh, S., Sharan, P. S., Mishra, K., Govind, N., \& Singhai, A. K. (2011). Qualitative and quantitative profile of curcumin from ethanolic extract of Curcuma longa. Int Res J Pharm, 2(4), 180-184.

6. Ayyanar, M., \& Ignacimuthu, S. (2009). Herbal medicines for wound healing among tribal people in Southern India: Ethnobotanical and Scientific evidences. International journal of Applied research in Natural products, 2(3), 29-42.

7. Soni, H., Nayak, G., Mishra, K., Singhai, A. K., \& Pathak, A. K. (2010). Pharmacognostic and phytochemical evalution of peel of Punica granatum. International Journal of Pharmacognosy and Phytochemical Research, 2(2), 56-58.
8. Soni, H., Nayak, G., Mishra, K., Singahi, A. K., \& Pathak, A. K. (2010). Pharmacognostic and Phytochemical Evalution of Leaves of Coleus aromaticus. International Journal of Pharmacology and Biological Sciences, 4(4), 71-74.

9. Soni, H., Nayak, G., Patel, S. S., Mishra, K., Singhai, A. K., Swarnkar, P., \& Pathak, A. K. (2011). Synergistic effect of polyherbal suspension of Punica granatum and Coleus aromaticus in evaluation of wound healing activity. J Herbal Med Toxicol, 5(1), 111-115.

10. Coolen, N. A., Vlig, M., Van Den Bogaerdt, A. J., Middelkoop, E., \& Ulrich, M. M. (2008). Development of an in vitro burn wound model. Wound repair and regeneration, 16(4), 559-567. 